\title{
Field-Induced Electron Emission from Nanoporous Carbons
}

\author{
Alexander Arkhipov, ${ }^{1}$ Sergey Davydov, ${ }^{1}$ Pavel Gabdullin, ${ }^{1}$ Nikolay Gnuchev, ${ }^{1}$ \\ Alexandr Kravchik, ${ }^{2}$ and Svyatoslav Krel ${ }^{1}$ \\ ${ }^{1}$ Saint Petersburg State Polytechnic University, 29 Politekhnicheskaya, Saint Petersburg 195251, Russia \\ ${ }^{2}$ Ioffe Physico-Technical Institute, 26 Politekhnicheskaya, Saint Petersburg 194021, Russia \\ Correspondence should be addressed to Alexander Arkhipov; arkhipov@rphf.spbstu.ru
}

Received 12 July 2014; Accepted 17 November 2014; Published 7 December 2014

Academic Editor: Shiren Wang

Copyright (C) 2014 Alexander Arkhipov et al. This is an open access article distributed under the Creative Commons Attribution License, which permits unrestricted use, distribution, and reproduction in any medium, provided the original work is properly cited.

Influence of fabrication technology on field electron emission properties of nanoporous carbon (NPC) was investigated. Samples of NPC derived from different carbides via chlorination at different temperatures demonstrated similar low-field emission ability with threshold electric field $2-3 \mathrm{~V} / \mu \mathrm{m}$. This property correlated with presence of nanopores with characteristic size $0.5-1.2 \mathrm{~nm}$, determining high values of specific surface area $\left(>800 \mathrm{~m}^{2} / \mathrm{g}\right)$ of the material. In most cases, current characteristics of emission were approximately linear in Fowler-Nordheim coordinates (excluding a low-current part near the emission threshold), but the plots' slope angles were in notable disagreement with the known material morphology and electronic properties, unexplainable within the frames of the classical emission theory. We suggest that the actual emission mechanism for NPC involves generation of hot electrons at internal boundaries and that emission centers may be associated with relatively large (20-100 nm) onion-like particles observed in many microscopic images. Such particles can serve two functions: to provide additional "internal" enhancement of the electric field and to inhibit relaxation of hot charge carriers due to the "phonon bottleneck" effect.

\section{Introduction}

In the recent decade, the carbon-based field emitters developed into a promising option for diverse practical applications $[1,2]$. Initially, carbon nanotubes were the nanocarbon form that attracted the most part of attention. However, the technological processes for controlled growth of aligned nanotube arrays remain relatively expensive. Furthermore, the problem of their degradation under operational conditions has not yet been solved [3-6], and all efforts directed to its solution yielded only limited success. These drawbacks expand the focus of emission investigations onto other types of nanocarbon-with relatively smooth surface topography, heterogeneous composition, and (more or less) disordered structure. The phenomenon of low-field electron emission for such materials cannot be explained by the classical FowlerNordheim (FN) theory, so a few principally different emission models were proposed for them in the past years [7-16]. Most commonly, the models involve a multistage tunnel transfer of electrons via domains with different electronic properties $[2,17-26]$.

In the presented work, we investigated field-emission properties of nanoporous carbon (NPC) [27-34] - one of all-carbon materials with disordered nanoscale structure. Due to developed pore/skeleton interface, homogeneity of pore size, strong adsorption ability, relatively high electric conductivity, and mechanical strength, the NPC materials give considerable promise for diverse applications, including manufacture of field electron emitters [35] for microwave, light, and X-ray sources, plasma devices, space thrusters, and microelectronic components and gauges. NPC structure can be efficiently controlled via parameters of fabrication process, and our work was initially focused on investigation of correlation between structural and emission properties of this nanocarbon. Such data may be used to propose a relevant model of low-field electron emission from NPC and further to develop a technology for fabrication of competitive cold cathodes on the basis of this material. 
TABLE 1: Properties of NPC powders produced from different carbides.

\begin{tabular}{lccccc}
\hline Original carbide & $\begin{array}{c}\text { Apparent density, } \\
\mathrm{g} / \mathrm{cm}^{3}\end{array}$ & $\begin{array}{c}\text { Pycnometric density, } \\
\mathrm{g} / \mathrm{cm}^{3}\end{array}$ & Pore volume, $\mathrm{cm}^{3} / \mathrm{g}$ & $\begin{array}{c}\text { Specific surface area, } \\
\mathrm{m}^{2} / \mathrm{g}\end{array}$ & $\begin{array}{c}\text { Pore diameter, } \\
\mathrm{nm}\end{array}$ \\
\hline $\mathrm{ZrC}$ & 0.91 & 2.15 & 0.58 & 1000 & 0.7 \\
$\mathrm{TiC}$ & 0.99 & 2.20 & 0.55 & 1100 & 0.8 \\
$\mathrm{~B}_{4} \mathrm{C}$ & 0.55 & 2.20 & 0.75 & 1310 & 4.0 \\
$\mathrm{Mo}_{2} \mathrm{C}$ & 0.53 & 2.15 & 0.77 & 1740 & 4.0 \\
\hline
\end{tabular}

TABLE 2: Properties of NPC powders produced from SiC at different temperatures.

\begin{tabular}{|c|c|c|c|c|c|c|}
\hline $\begin{array}{l}\text { Chlorination } \\
\text { temperature, }{ }^{\circ} \mathrm{C}\end{array}$ & $\begin{array}{l}\text { Apparent density, } \\
\mathrm{g} / \mathrm{cm}^{3}\end{array}$ & $\begin{array}{l}\text { Pycnometric } \\
\text { density, } \mathrm{g} / \mathrm{cm}^{3}\end{array}$ & $\begin{array}{c}\text { Nanopore } \\
\text { volume, } \mathrm{cm}^{3} / \mathrm{g}\end{array}$ & $\begin{array}{c}\text { Mesopore } \\
\text { volume, } \mathrm{cm}^{3} / \mathrm{g}\end{array}$ & $\begin{array}{c}\text { Specific surface } \\
\text { area, } \mathrm{m}^{2} / \mathrm{g}\end{array}$ & Pore diameters, nm \\
\hline 700 & 0.52 & 2.18 & 0.42 & 0.10 & 1280 & $0.55 ; 1.2$ \\
\hline 900 & 0.50 & 2.12 & 0.34 & 0.16 & 1253 & $0.52 ; 0.8 ; 1.2$ \\
\hline 1200 & 0.43 & 1.99 & 0.27 & 0.16 & 866 & $0.55 ; 0.9 ; 6.0$ \\
\hline 2000 & 0.20 & 1.30 & 0.0 & 0.20 & 46 & 22.0 \\
\hline
\end{tabular}

\section{Sample Preparation and Morphology}

Samples of nanoporous carbon were fabricated by hightemperature chlorination of carbide powders which led to chemical removal of all noncarbon atoms and breaking of all chemical bonds. Grains of the resulting all-carbon material inherited outer shapes and volume from the initial carbide powder, but the material's structure became much more complicated-comprised of graphitic, diamond-like, and disordered domains and pores. We took different primary carbides and varied chlorination temperature to obtain samples with different structure and properties. The samples were studied by the methods of X-ray diffraction, adsorption analysis, helium pycnometry, and electron and atomic force microscopy (SEM, TEM, and AFM). Detailed description of production and characterization procedures may be found elsewhere [32, 33].

Typical structural parameters of NPC samples produced from carbides of metals $(\mathrm{Zr}, \mathrm{Ti}$, and $\mathrm{Mo}$ ) and boron are listed in Table 1 and demonstrate diversity of the investigated NPC species. For the products of chlorination of $\mathrm{B}_{4} \mathrm{C}$ and $\mathrm{Mo}_{2} \mathrm{C}$, the mean pore size was approximately 5 times greater than that for derivatives of $\mathrm{ZrC}$ and $\mathrm{TiC}$. As a result, the apparent density in the latter case was almost two times greater, while the values of pycnometric density (i.e., density of carbon skeleton, with volume of the pores excluded from consideration) for all samples were close to the density of graphite.

Silicon carbide was also used for fabrication of NPC samples. The process of its chlorination was performed at different temperatures. Parameters of different NPC specimens originating from silicon carbide are given in Table 2. The pore size composition for them was less homogeneous and it changed with variation of chlorination temperature. In the samples prepared at relatively low temperatures $\left(700-900^{\circ} \mathrm{C}\right)$, the pore size was close to $1 \mathrm{~nm}$. If the treatment temperature was higher $\left(1200^{\circ}\right)$, larger pores appeared and the sample density (in both definitions) decreased, apparently due to

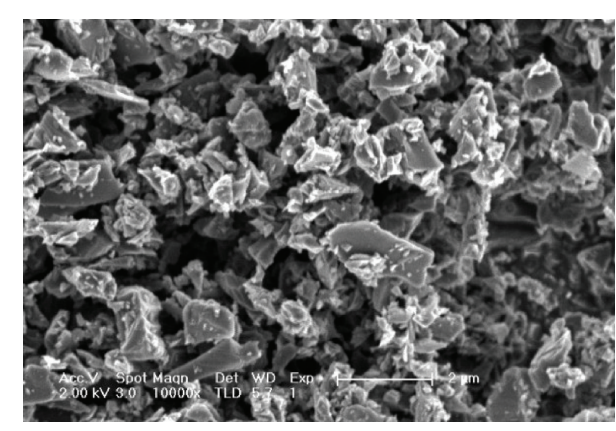

FIgURE 1: A typical overview SEM image of an NPC sample (SiC, $\left.1200^{\circ} \mathrm{C}\right)$.

higher chlorine etching efficiency in respect to carbon atoms. After treatment at $2000^{\circ} \mathrm{C}$, only large pores (mesopores) remained in the sample; the carbon skeleton lost more than a half of its mass and underwent reconstruction with dramatic reduction of specific surface area.

Microscopic images gave more detailed information on the structure of investigated NPC samples. All the largescale SEM images of samples' surface were similar to the one presented in Figure 1 and showed $\mu \mathrm{m}$ - and sub- $\mu \mathrm{m}$-sized irregular particles, presumably retaining their outer shapes from original carbide powders.

High-resolution TEM images (Figures 2(a)-2(c)) revealed the atomic-scale structure of NPC samples, which included both amorphous (Figure 2(c)) and crystalline domains of faceted (Figure 2(a)) or rounded (Figure 2(b)) shapes. The interplane distances in the ordered regions $(\sim 0.35 \mathrm{~nm})$ correspond to the lattice period of graphite. Typical sizes of domains distinguished in TEM and AFM images varied between 20 and $100 \mathrm{~nm}$, though sometimes even larger faceted crystallites were observed (Figure 2(d)). For NPC samples derived from the same carbide, the degree of crystallinity generally increased with chemical treatment temperature $[31,34]$. 


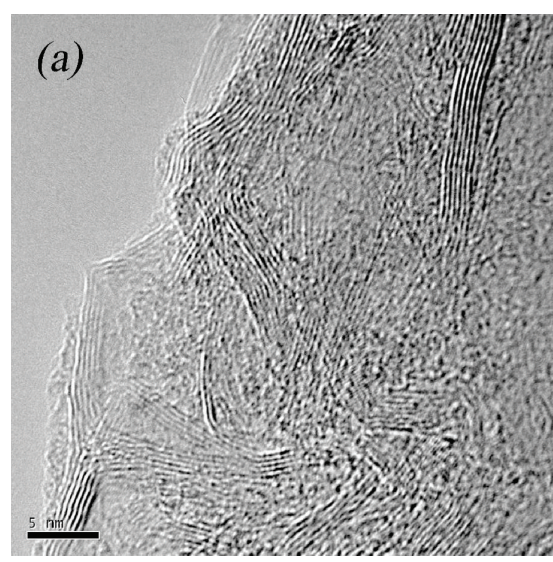

(a)

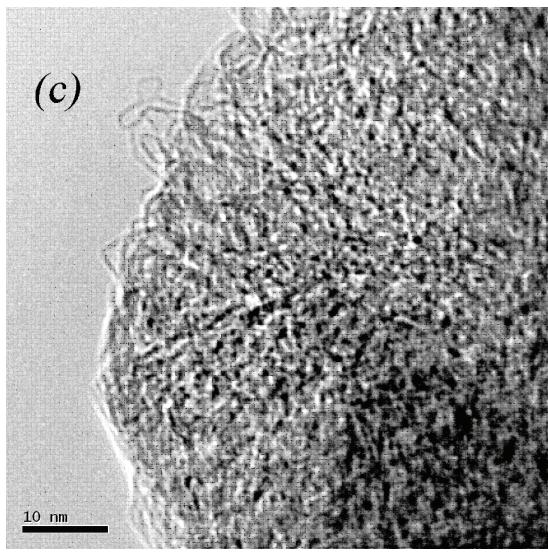

(c)

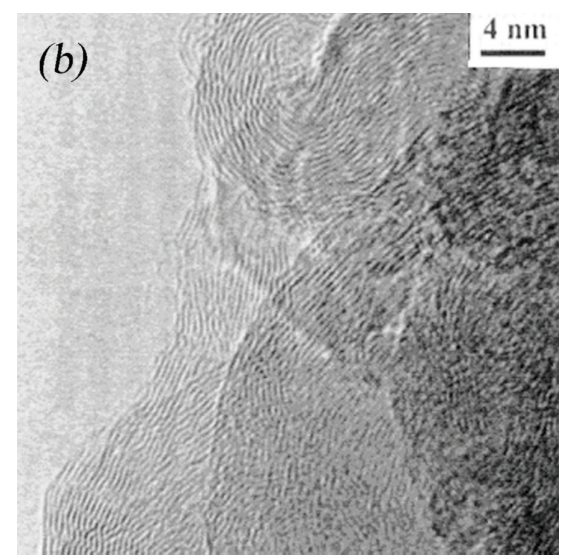

(b)

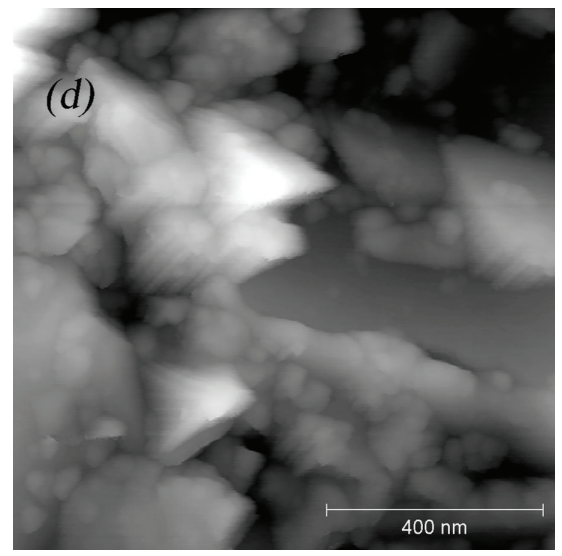

(d)

FIGURE 2: Typical nm-scale morphological elements of NPC surface in HR TEM (a-c) and AFM (d) images.

\section{Emission Properties}

Emission properties of NPCs were tested in the layout described previously in [35]. The emitter samples were prepared by deposition of NPC powders at metal substrates. The electric field was applied to a sample using a cylindrical flat-top tungsten anode, $6 \mathrm{~mm}$ in diameter, in vacuum better than $10^{-6}$ Torr. The field gap width was typically $0.5 \mathrm{~mm}$. It was possible to vary the sample temperature between $20^{\circ} \mathrm{C}$ and $400^{\circ} \mathrm{C}$, to remove volatile contaminants and to improve emission properties via relatively soft thermofield treatment procedures [35].

All investigated NPC species demonstrated comparable emission properties. Emission characteristics of the best samples of NPCs produced from different carbides are showed in Figure 3. The threshold field (corresponding to appearance of a measurable current) was as low as $2-3 \mathrm{~V} / \mu \mathrm{m}$ for all these samples. Unfortunately, other samples of the same series, fabricated in the same technological process, demonstrated much worse emission properties. This means that the technology we used remains relatively unstable and/or that emission parameters were often determined by poorly controlled features of the samples.
The emitters prepared from silicon carbide demonstrated similar emission properties for all chlorination temperatures (Figure 4), excluding the case of the highest temperature $2000^{\circ} \mathrm{C}$. This special form of NPC with very low specific surface (see Table 2) never yielded any emission current in any of our experiments.

Being plotted in FN coordinates (Figures 3(b) and 4(b)), the emission characteristics were approximately linear. In accordance with the classical field-emission model, their slope angles may be used to calculate the combined parameter $\left(\varphi^{3 / 2} / \beta\right)$, where $\varphi$ is emitter work function and $\beta$ is field enhancement factor. For the showed plots, this parameter varies between $2.0 \cdot 10^{-3}$ and $6.5 \cdot 10^{-3} \mathrm{eV}^{3 / 2}$. Taking $\varphi=4.5 \mathrm{eV}$ (a typical value for various forms of carbon [14, 36, 37]), we obtain estimates of the field enhancement factor $\beta$ between 1500 and 4500, which is obviously too high for the surface topography revealed by the microscopic studies. Furthermore, assuming more plausible value $\beta=10$, we can estimate the work function as $\varphi=(0.07-0.16) \mathrm{eV}$. For a material with such work function, heating to $400^{\circ} \mathrm{C}$ would result in thermal emission with space-charge-limited current density $>10 \mathrm{~A} / \mathrm{cm}^{2}$, which definitely was not observed in 


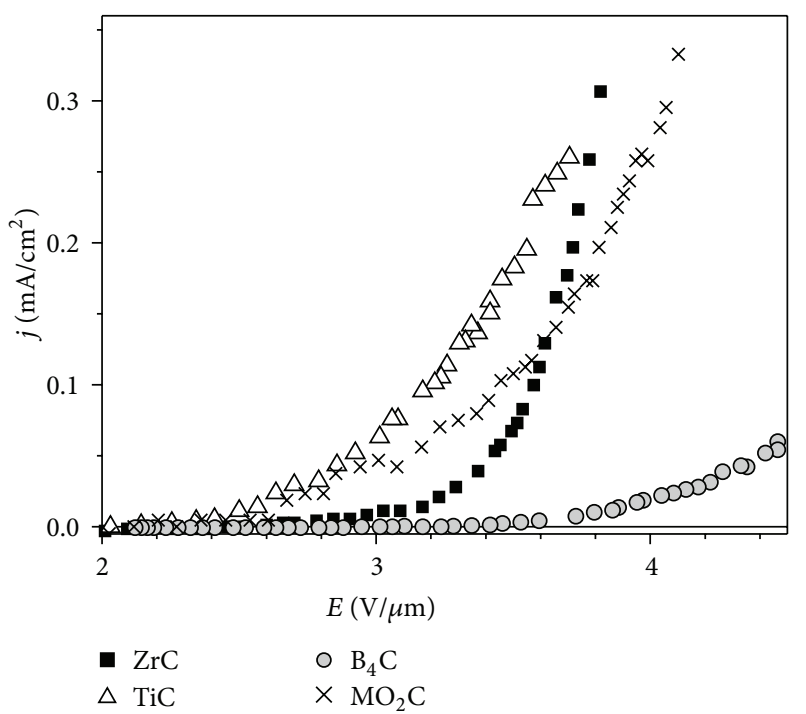

(a)

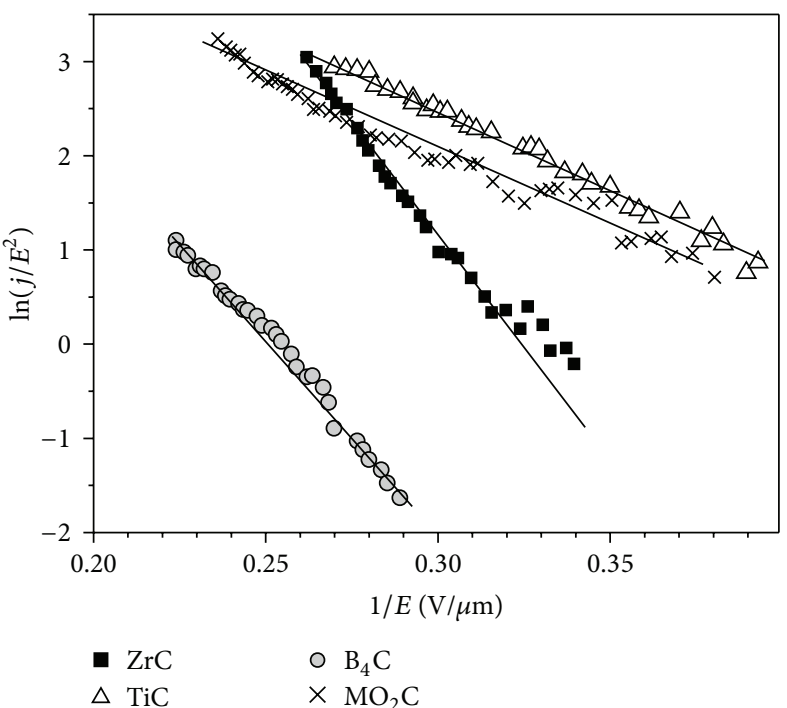

(b)

FIgURE 3: $I-V$ characteristics in straight (a) and FN (b) coordinates for NPC samples fabricated from the carbides indicated in the legend.

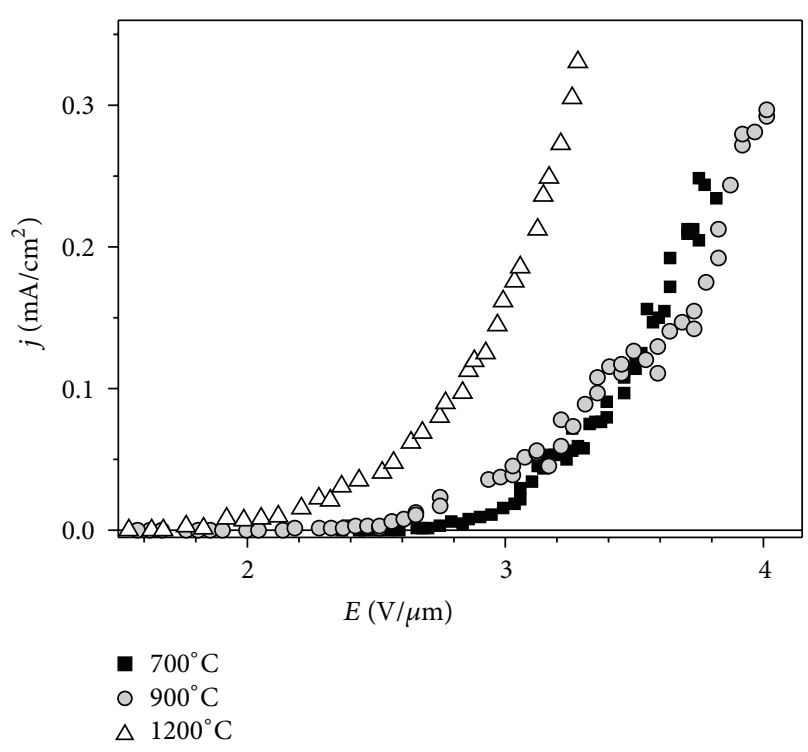

(a)

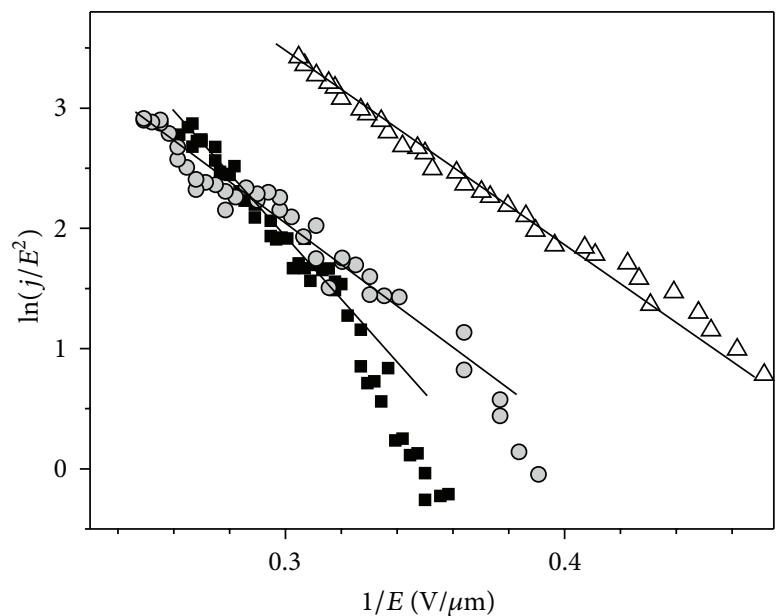

- $700^{\circ} \mathrm{C}$

○ $900^{\circ} \mathrm{C}$

$\triangle 1200^{\circ} \mathrm{C}$

(b)

FIGURE 4: $I$ - $V$ characteristics in straight (a) and FN (b) coordinates for NPC samples fabricated from SiC by chemical treatment at different temperatures.

the experiments. Thus, we can conclude that the experimental data apparently disagree with the FN emission mechanism.

Further disagreement might often be found at lowcurrent part of the measured $I-V$ plots, near the emission threshold. Figure 5 represents a few typical emission plots with such features as shelves (Figure 5(a)) and even dips (Figure 5(c), the interval formally characterized by negative differential conductance) that reproduced themselves on both plot branches, measured in increasing and decreasing field. Such features appeared too frequently to result from random current fluctuations. Their reproducibility also excludes a number of possible explanations: thermal effects, removal of contaminant layers, and so forth. Deviations from the exponential law were most typical for emission current values below 3-5 $\mu \mathrm{A}$, but sometimes they were seen at much higher currents, as it is demonstrated in Figure 5(b).

The contradiction between the observed "fine structure" at the low-current parts of $I-V$ emission plots and smooth exponential growth at higher currents can be naturally explained by statistical averaging of individual emission characteristics of local emission centers, which may themselves have complicated shapes. Near the emission threshold 


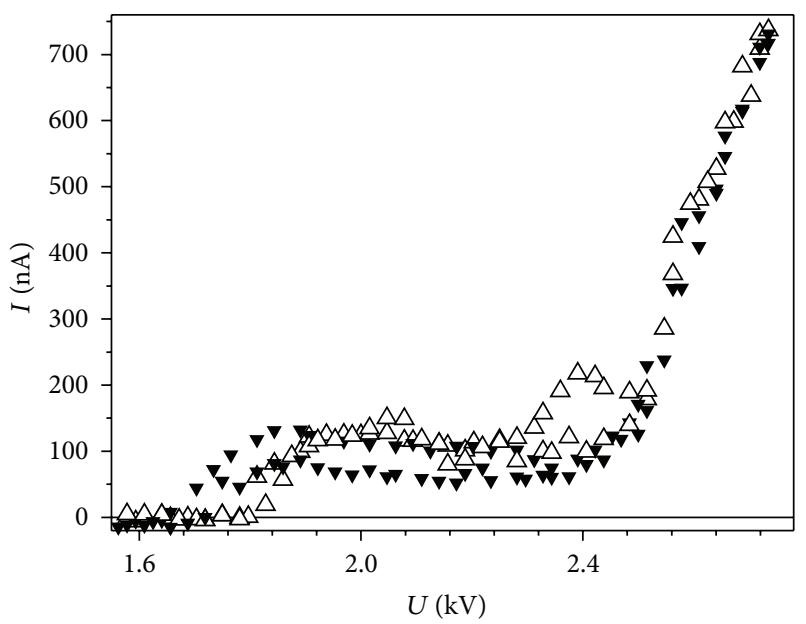

(a)

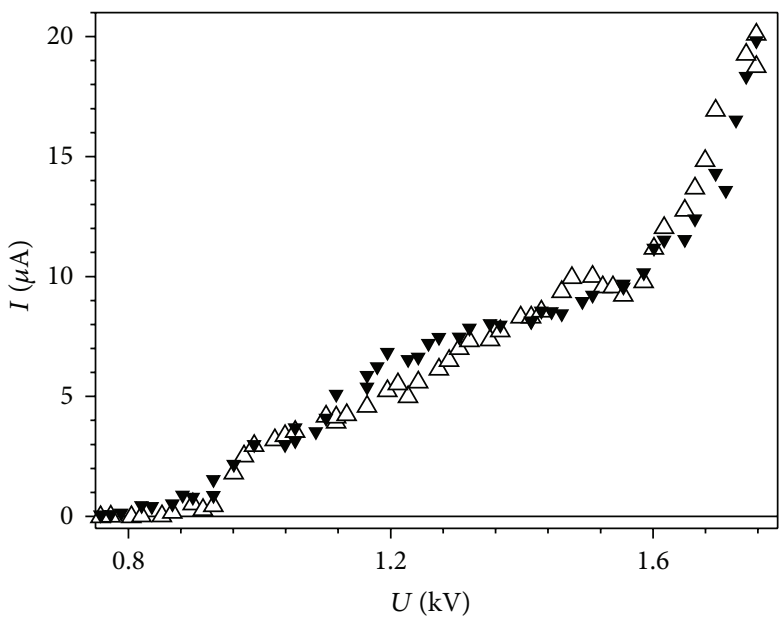

(b)

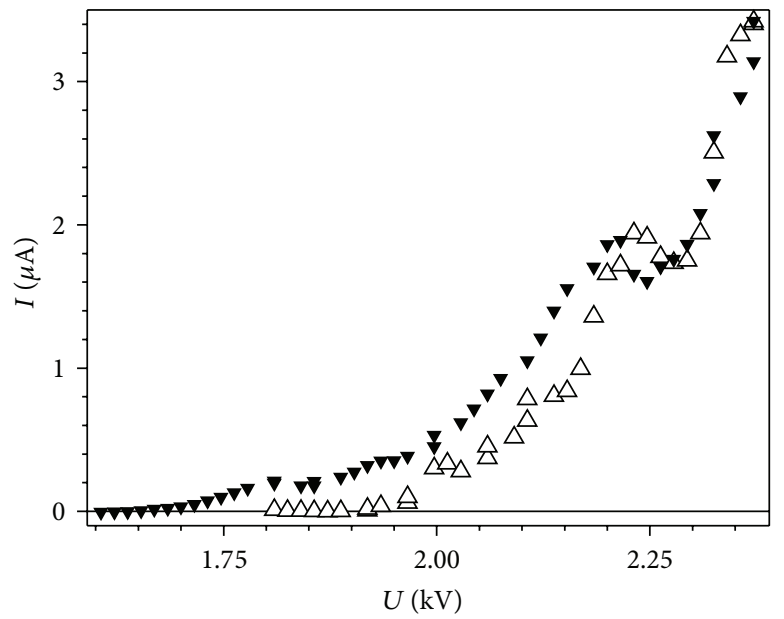

(c)

FIGURE 5: Emission $I-V$ plots for NPC samples with typical reproducible deviations from exponential shape. Empty and black symbols mark the data acquisition direction: $U \uparrow$ and $U \downarrow$, respectively. The field gap width is $0.75 \mathrm{~mm}$, and curve measurement time was $\sim 1 \mathrm{~min}$.

we observed emission from a limited number of the most efficient centers [38]. As the field was being increased, this number grew and the individual features of emission were smoothed out.

Thus, the performed experiments with different NPC species have demonstrated that they can efficiently emit electrons in relatively weak electric field, if only they have well-developed $\mathrm{nm}$-scale structure characterized by large specific surface area of nanopores. As for many other forms of nanocarbon, the phenomenon of low-field emission and properties of emission characteristics cannot be adequately described by the Fowler-Nordheim theory, so probably the mechanism of direct electron transfer to the vacuum from the emitter Fermi level is irrelevant in this case.

\section{Discussion}

Some authors $[38,39]$ associate the phenomenon of lowfield emission from all forms of nanocarbon with the enhancement of electric field at high-aspect-ratio elements (nanotubes, nanowires, and fibers), even when these elements are not introduced intentionally and are present at the emitter surface in relatively low numbers as a technological contaminant. Even though this explanation may be correct for some of the discussed emitters, we think that in the NPC materials investigated in this work the emission mechanism is different. Besides the fact of low-field emission, the actual emission model for NPC has also to explain other experimentally observed (and described in this and previous publications, for instance, [40-42]) features of emission behavior, including the following:

(i) the reproducible "fine structure" of emission characteristics near the threshold field discussed above;

(ii) hysteresis of emission from NPC in pulsed field (at sub- $\mu$ s and even $\mu$ s time scale) described in previous publications [40];

(iii) results of independent definition of field enhancement factor $(\beta \approx 15)$ and energy position of "emitting" 


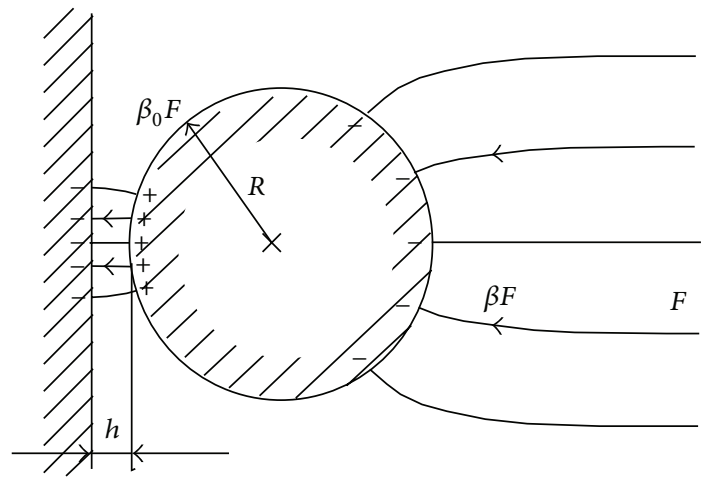

(a)

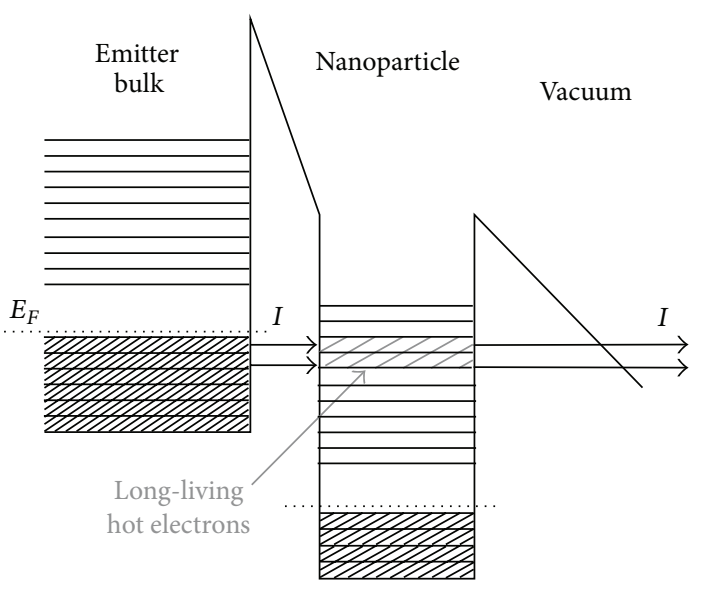

(b)

FIGURE 6: The suggested structure of an active emission center on the NPC surface: schematic geometry (a) and energy diagram (b).

electron states in NPC (the electron affinity $\chi_{S} \approx 0.3-$ $0.6 \mathrm{eV}$, i.e., much lower than work function for carbon $\varphi=4.5-5.0 \mathrm{eV}$ ), performed on the basis of emission characteristics in pulsed field [41];

(iv) relatively wide (up to $1 \mathrm{eV}$ ) energy distributions of the emitted electrons [42].

We think that all these features of emission from NPC may be explained in terms of the two-stage model of emission mechanism [2, 17-26] with a few important modifications discussed below. According to this model, electrons are transferred from the emitter bulk electron states near Fermi level $\left(E_{F}\right)$ to vacuum not directly but in two successive steps via some (probably different for different materials) intermediate states localized near the emitter surface, with energies substantially higher than $E_{F}$. If electrons are elevated onto such nonequilibrium states, they can be effectively emitted to vacuum because the surface potential barrier is lower in this case and more transparent for them than for electrons at Fermi level. Yet for realization of this emission mechanism, the following conditions must be satisfied:

(1) the applied electric field should penetrate into the emitter material to produce free energy that is necessary to elevate electrons to high-energy states (i.e., to generate hot electrons);

(2) inside the emitter, the field should be concentrated internal boundaries to be able to provide some electrons with relatively large (eV-scale) additional energy;

(3) the hot electrons should be able to propagate to the vacuum boundary and remain there for a considerable time without thermalization.

The available information on the NPC structure and properties suggests that all the listed conditions may be met in its case.

According to publications [29-34] and our own microscopic data, the NPC is a porous conglomerate of small (1-2 nm) graphene sheets mixed with larger onion-like or graphitic-shelled particles, up to $50-200 \mathrm{~nm}$ in size. Electronic properties of the material are those of a p-type semiconductor [30], which means nonzero band gap and Fermi level position near the valence band top. The excessive holes appear due to electron trapping at interface boundary states, and thus all the crystalline volumes are charged positively relative to their boundaries. Due to strong band bending, the nanodomains are separated from each other by tunnel junctions allowing external field to penetrate in the material.

Polarization of domains leads to enhancement of the applied field at the junctions (Figure 6). The enhancement factor can be roughly estimated via solution of electrostatic problem considering a conductive sphere (the nanodomain) with radius $R$ placed at a small distance $h$ (junction) from a conductive plane (the rest of the emitter). In this system, the electric field $F$ applied normally to the plane is locally increased by the factor $\beta_{0}=A R / h$, where $A \approx 0.5$. For example, if the particle size is $80 \mathrm{~nm}$ and junction width is $0.4 \mathrm{~nm}$, the additional internal field enhancement can reach 100, which may be sufficient for our model. A similar problem was investigated in [43] for ellipsoidal $s p^{2}$ particles in a:C layer at a conductive substrate, and enhancement factors up to 300 were considered. Potential difference between adjacent domains can reach $1 \mathrm{~V}$ in electric field with moderate magnitude $<10 \mathrm{~V} / \mu \mathrm{m}$, and the electrons injected through the interface junctions will have energies much higher than the local Fermi level (Figure 6). However, to increase emission efficiency, these hot electrons have to reach the outer emitter boundary and remain in its vicinity for a relatively long time without relaxation. According to recent studies [44, 45], such possibility appears if the considered medium is comprised of nanoparticles with size $\sim 30 \mathrm{~nm}$ or smaller. Electron relaxation time dramatically increases (in comparison with larger crystallites) due to so-called "phonon bottleneck effect" [4648 ] associated with reduced density of states in conductance band of nanocrystals, leaving energy gaps between adjacent levels exceeding maximum phonon energy for this lattice. Therefore, the most efficient mechanism of energy lossesthe electron-phonon interaction-is practically excluded. 
Recombination time for hot charge carriers grows to values exceeding $1 \mathrm{~ns}$, which is more than sufficient for electrons injected from the "back" side of a surface-layer crystallite to propagate across the grain. If the relaxation is very slow, it can even explain the hysteresis of characteristics of emission in pulsed field observed in [40].

So, all the necessary conditions for enhanced electron emission may be fulfilled due to the presence of conductive nanoparticles in the structure of NPC materials. These particles are presumably able to concentrate electric field at internal interfaces. This property "replaces" field enhancement at outer morphology elements of emitters based on nanotubes and fibers and can be even preferable for practical use- the region of concentrated field and current is protected from external impacts, such as ionic bombardment. On the surface, where these factors are present, the field is less concentrated, which can result in higher emitter durability. Another function of nanoparticles may consist in longtime conservation of hot electrons injected from the emitter bulk - not only at the bottom of the conductance band (as, for instance, in diamond), but also practically at any energy levels. Hence, the property of low affinity is not necessary for nanostructured emitters, and nanoparticles of $s p^{2}$ carbon can facilitate emission as well as diamond ones. The former may even be preferable, because broad band gap (in diamond) can hamper the process of generation of hot electrons at tunnel junctions if potential difference between adjacent grains is not large enough (Figure 6).

Among other properties, the proposed model explains the complicated shapes of current characteristics of emission from nanocarbon materials, reported in this (Figure 5) and many previous works. Spectra of allowed energy levels for nanoparticles are more complicated than for larger crystals. Hence, field dependency of the current injected into such a particle (domain) through a tunnel junction may be complex and even nonmonotonous (including "negativeconductivity" intervals), which would be reflected by its emission characteristics.

\section{Conclusions}

The performed investigation of emission properties of nanoporous carbon demonstrated that materials of this type are capable of low-field electron emission. Their emission properties showed relatively weak dependency of structural details determined by technology of their fabrication, for example, the composition of the original carbide and the temperature of chemical treatment. Among all the NPC samples tested in this work, the only exclusion made those produced from $\mathrm{SiC}$ in chlorination process performed at the highest temperature $\left(2000^{\circ} \mathrm{C}\right)$. These samples lost their nanoscale structure and produced no emission current in the investigated range of field magnitudes. We explain the obtained results in terms of the two-stage emission model. We think that $20-200 \mathrm{~nm}$ graphitic particles observed at the surface of NPC samples can play the main role in the emission mechanism in two ways: (1) determining substantial enhancement of applied electric field at junctions separating them from the rest of emitter bulk and (2) providing conditions for conservation of nonequilibrium energy distribution of electrons injected into such particles through these junctions.

\section{Conflict of Interests}

The authors declare that there is no conflict of interests regarding the publication of this paper.

\section{Acknowledgment}

This work was partially supported by the Russian Ministry of Science and Education (Grant no. 11.G34.31.0041).

\section{References}

[1] N. S. Xu and S. E. Huq, "Novel cold cathode materials and applications," Materials Science and Engineering R: Reports, vol. 48, no. 2-5, pp. 47-190, 2005.

[2] A. N. Obraztsov, "Vacuum electronic applications of nanocarbon materials," in Nanoengineered Nanofibrous Materialas, S. Guceri, Y. G. Gogotsi, and V. Kusnetsov, Eds., pp. 329-339, Kluwer Academic Publishers, Dordrecht, The Netherlands, 2004.

[3] Z. L. Tolt, C. McKenzie, R. Espinosa, S. Snyder, and M. Munson, "Carbon nanotube cold cathodes for application in low current x-ray tubes," Journal of Vacuum Science and Technology B, vol. 26, no. 2, pp. 706-710, 2008.

[4] C.-W. Baik, J. Lee, J. H. Choi et al., "Structural degradation mechanism of multiwalled carbon nanotubes in electrically treated field emission," Applied Physics Letters, vol. 96, no. 2, Article ID 023105, 2010.

[5] X. H. Liang, S. Z. Deng, N. S. Xu, J. Chen, N. Y. Huang, and J. C. She, "Noncatastrophic and catastrophic vacuum breakdowns of carbon nanotube film under direct current conditions," Journal of Applied Physics, vol. 101, no. 6, Article ID 063309, 2007.

[6] G. S. Bocharov and A. V. Eletskii, "Degradation of a CNTbased field emission cathode due to ion sputtering," Fullerenes Nanotubes and Carbon Nanostructures, vol. 20, no. 4-7, pp. 444450, 2012.

[7] H. Yamaguchi, T. Masuzawa, S. Nozue et al., "Electron emission from conduction band of diamond with negative electron affinity," Physical Review B-Condensed Matter and Materials Physics, vol. 80, no. 16, Article ID 165321, 2009.

[8] T. Masuzawa, Y. Sato, Y. Kudo et al., "Correlation between low threshold emission and $\mathrm{C}-\mathrm{N}$ bond in nitrogen-doped diamond films," Journal of Vacuum Science and Technology B, vol. 29, no. 2, Article ID 02B119, 2011.

[9] A. T. T. Koh, Y. M. Foong, J. Yu et al., "Understanding tube-like electron emission from nanographite clustered films," Journal of Applied Physics, vol. 110, no. 3, Article ID 034903, 2011.

[10] J. D. Carey and S. R. P. Silva, "Field emission from amorphous semiconductors," Solid-State Electronics, vol. 45, no. 6, pp. 10171024, 2001.

[11] A. V. Karabutov, V. D. Frolov, V. I. Konov, V. G. Ralchenko, S. K. Gordeev, and P. I. Belobrov, "Low-field electron emission of diamond/pyrocarbon composites," Journal of Vacuum Science \& Technology B, vol. 19, no. 3, pp. 965-970, 2001. 
[12] S. F. Ahmed, M.-W. Moon, and K.-R. Lee, "Enhancement of electron field emission property with silver incorporation into diamondlike carbon matrix," Applied Physics Letters, vol. 92, no. 19, Article ID 193502, 2008.

[13] J. Robertson, "Mechanisms of electron field emission from diamond, diamond-like carbon, and nanostructured carbon," Journal of Vacuum Science and Technology B: Microelectronics and Nanometer Structures, vol. 17, no. 2, pp. 659-665, 1999.

[14] A. Ilie, A. Hart, A. J. Flewitt, J. Robertson, and W. I. Milne, "Effect of work function and surface microstructure on field emission of tetrahedral amorphous carbon," Journal of Applied Physics, vol. 88, no. 10, pp. 6002-6010, 2000.

[15] R. G. Forbes, "Low-macroscopic-field electron emission from carbon films and other electrically nanostructured heterogeneous materials: hypotheses about emission mechanism," SolidState Electronics, vol. 45, no. 6, pp. 779-808, 2001.

[16] J. D. Carey and S. R. P. Silva, "Disorder, clustering, and localization effects in amorphous carbon," Physical Review B: Condensed Matter and Materials Physics, vol. 70, no. 23, Article ID 235417, pp. 1-8, 2004.

[17] J. D. Jarvis, H. L. Andrews, B. Ivanov et al., "Resonant tunneling and extreme brightness from diamond field emitters and carbon nanotubes," Journal of Applied Physics, vol. 108, no. 9, Article ID 094322, 2010.

[18] M. Tordjman, A. Bolker, C. Saguy, and R. Kalish, "Temperature dependence of reversible switch-memory in electron field emission from ultrananocrystalline diamond," Applied Physics Letters, vol. 101, no. 17, Article ID 173116, 2012.

[19] K. Nose, R. Fujita, M. Kamiko, and Y. Mitsuda, "Electron field emission from undoped polycrystalline diamond particles synthesized by microwave-plasma chemical vapor deposition," Journal of Vacuum Science and Technology B, vol. 30, no. 1, Article ID 011204, 2012.

[20] M. W. Geis, N. N. Efremow, K. E. Krohn et al., "A new surface electron-emission mechanism in diamond cathodes," Nature, vol. 393, no. 6684, pp. 431-435, 1998.

[21] S. R. P. Silva, G. A. J. Amaratunga, and K. Okano, "Modeling of the electron field emission process in polycrystalline diamond and diamond-like carbon thin films," Journal of Vacuum Science and Technology B: Microelectronics and Nanometer Structures, vol. 17, no. 2, pp. 557-561, 1999.

[22] X. Shi, L. K. Cheah, B. K. Tay, and S. R. P. Silva, "Electron field emission from surface treated tetrahedral amorphous carbon films," Applied Physics Letters, vol. 74, no. 6, pp. 833-835, 1999.

[23] A. N. Obraztsov and A. A. Zakhidov, "Low-field electron emission from nano-carbons," Diamond and Related Materials, vol. 13, no. 4-8, pp. 1044-1049, 2004.

[24] I. S. Altman, P. V. Pikhitsa, and M. Choi, "Two-process model of electron field emission from nanocarbons: temperature effect," Journal of Applied Physics, vol. 96, no. 6, pp. 3491-3493, 2004.

[25] S. Gupta, G. Morell, and B. R. Weiner, "Electron field-emission mechanism in nanostructured carbon films: a quest," Journal of Applied Physics, vol. 95, no. 12, pp. 8314-8320, 2004.

[26] W. G. Xie, J. Chen, S. Z. Deng, J. C. She, and N. S. Xu, "Effect of hydrogen treatment on the field emission of amorphous carbon film," Journal of Applied Physics, vol. 101, no. 8, Article ID 084315, 2007.

[27] S. H. Lai, K. L. Chang, H. C. Shih, K. P. Huang, and P. Lin, "Electron field emission from various morphologies of fluorinated amorphous carbon nanostructures," Applied Physics Letters, vol. 85, no. 25, pp. 6248-6250, 2004.
[28] M. Ojima, S. Hiwatashi, H. Araki, A. Fujii, M. Ozaki, and K. Yoshino, "Two-process model of electron field emission from nanocarbons: temperature effect," Applied Physics Letters, vol. 88, no. 5, Article ID 053103, 2006.

[29] E. Smorgonskaya, R. Kyutt, A. Danishevskii et al., "X-ray and HRTEM structural studies of bulk nanoporous carbon materials produced from carbides," Journal of Non-Crystalline Solids, vol. 299-302, no. 2, pp. 810-814, 2002.

[30] A. I. Vě̌nger, B. D. Shanina, A. M. Danishevskiǐ, V. V. Popov, S. K. Gordeev, and A. V. Grechinskaya, "Electrophysical studies of nanoporous carbon materials prepared of silicon carbide powders," Physics of the Solid State, vol. 45, no. 6, pp. 1197-1206, 2003.

[31] E. N. Hoffman, G. Yushin, M. W. Barsoum, and Y. Gogotsi, "Synthesis of carbide-derived carbon by chlorination of $\mathrm{Ti}_{2}$ AlC," Chemistry of Materials, vol. 17, no. 9, pp. 2317-2322, 2005.

[32] A. E. Kravchik, J. A. Kukushkina, V. V. Sokolov, and G. F. Tereshchenko, "Structure of nanoporous carbon produced from boron carbide," Carbon, vol. 44, no. 15, pp. 3263-3268, 2006.

[33] A. E. Kravchik, Y. A. Kukushkina, V. V. Sokolov, G. F. Tereshchenko, and E. A. Ustinov, "Structure of nanoporous carbon produced from titanium carbide and carbonitride," Russian Journal of Applied Chemistry, vol. 81, no. 10, pp. 1733-1739, 2008.

[34] M. E. Kompan, D. S. Krylov, and V. V. Sokolov, "Raman scattering in self-formed nanoporous carbon produced on the basis of silicon carbide," Semiconductors, vol. 45, no. 3, pp. 306311, 2011.

[35] V. B. Bondarenko, P. G. Gabdullin, N. M. Gnuchev et al., "Emissivity of powders prepared from nanoporous carbon," Technical Physics, vol. 49, no. 10, pp. 1360-1363, 2004.

[36] H. H. Busta, R. J. Espinosa, A. T. Rakhimov et al., "Performance of nanocrystalline graphite field emitters," Solid-State Electronics, vol. 45, no. 6, pp. 1039-1047, 2001.

[37] O. Gröning, L.-O. Nilsson, P. Gröning, and L. Schlapbach, "Properties and characterization of chemical vapor deposition diamond field emitters," Solid-State Electronics, vol. 45, no. 6, pp. 929-944, 2001.

[38] A. A. Zakhidov, A. N. Obraztsov, A. P. Volkov, and D. A. Lyashenko, "Statistical analysis of low-voltage electron emission from nanocarbon cathodes," Journal of Experimental and Theoretical Physics, vol. 97, no. 6, pp. 1240-1245, 2003.

[39] N. Koenigsfeld, R. Kalish, and A. Hoffman, "Improved field emission at electric-discharge-conditioned sites on diamond surfaces due to the formation of carbon nanotubes," Applied Physics Letters, vol. 82, no. 26, pp. 4687-4689, 2003.

[40] A. V. Arkhipov, M. V. Mishin, and I. V. Parygin, "Hysteresis of pulsed characteristics of field emission from nanocarbon materials," Surface and Interface Analysis, vol. 39, no. 2-3, pp. 149-154, 2007.

[41] A. V. Arkhipov, P. G. Gabdullin, and M. V. Mishin, "On possible structure of field-induced electron emission centers of nanoporous carbon," Fullerenes Nanotubes and Carbon Nanostructures, vol. 19, no. 1-2, pp. 86-91, 2011.

[42] S. N. Davydov, P. G. Gabdullin, and M. A. Ryumin, "Apparatus for investigating physical nature of nanoporous carbon structure field emission," in Proceedings of the Abstracts of International Workshop on Fullerenes and Atomic Clusters, p. 165, A.F. Ioffe Institute, St.Petersburg, Russia, July 2009. 
[43] G. C. Kokkorakis and J. P. Xanthakis, "Local electric field and enhancement factor around nanographitic structures embedded in amorphous carbon," Surface and Interface Analysis, vol. 39, no. 2-3, pp. 135-138, 2007.

[44] A. Pandey and P. Guyot-Sionnest, "Slow electron cooling in colloidal quantum dots," Science, vol. 322, no. 5903, pp. 929-932, 2008.

[45] W. A. Tisdale, K. J. Williams, B. A. Timp, D. J. Norris, E. S. Aydil, and X.-Y. Zhu, "Hot-electron transfer from semiconductor nanocrystals," Science, vol. 328, no. 5985, pp. 1543-1547, 2010.

[46] H. Benisty, "Reduced electron-phonon relaxation rates in quantum-box systems: theoretical analysis," Physical Review B, vol. 51, no. 19, pp. 13281-13293, 1995.

[47] T. Inoshita and H. Sakaki, "Electron-phonon interaction and the so-called phonon bottleneck effect in semiconductor quantum dots," Physica B: Condensed Matter, vol. 227, no. 1-4, pp. 373-377, 1996.

[48] A. J. Nozik, "Spectroscopy and hot electron relaxation dynamics in semiconductor quantum wells and quantum dots," Annual Review of Physical Chemistry, vol. 52, pp. 193-231, 2001. 

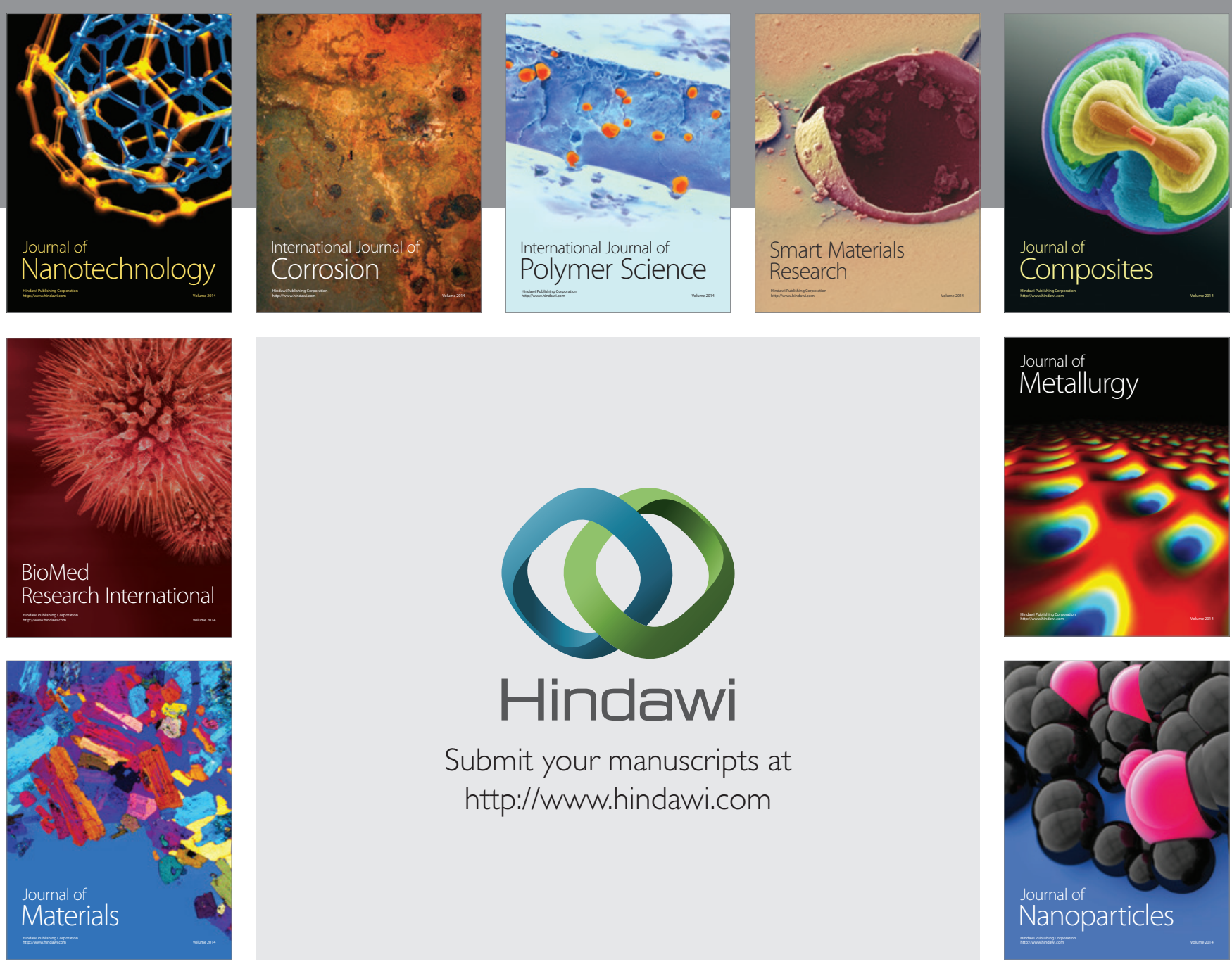

Submit your manuscripts at http://www.hindawi.com
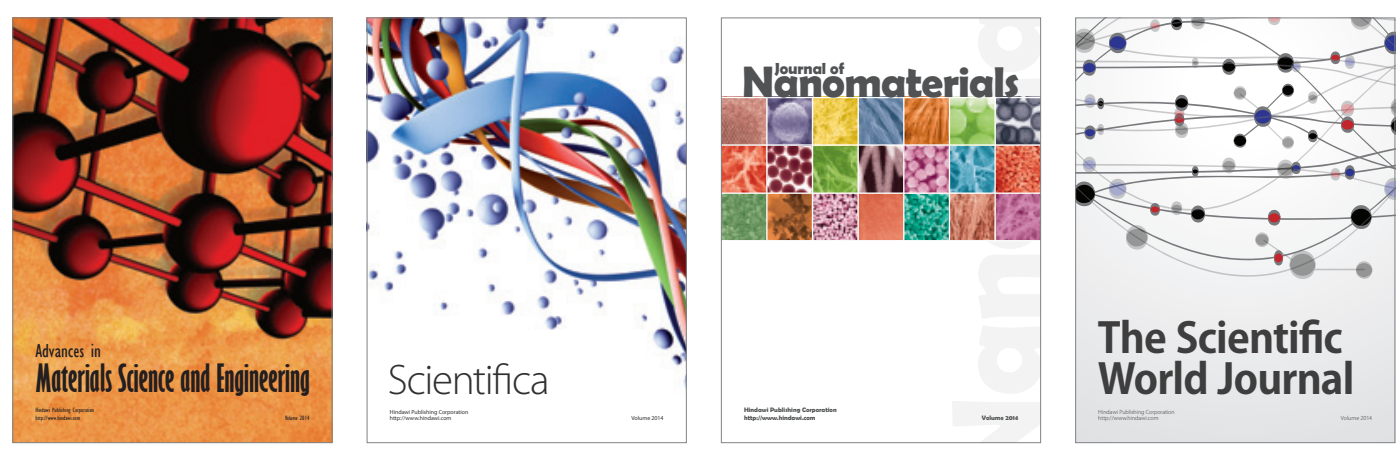

\section{The Scientific World Journal}
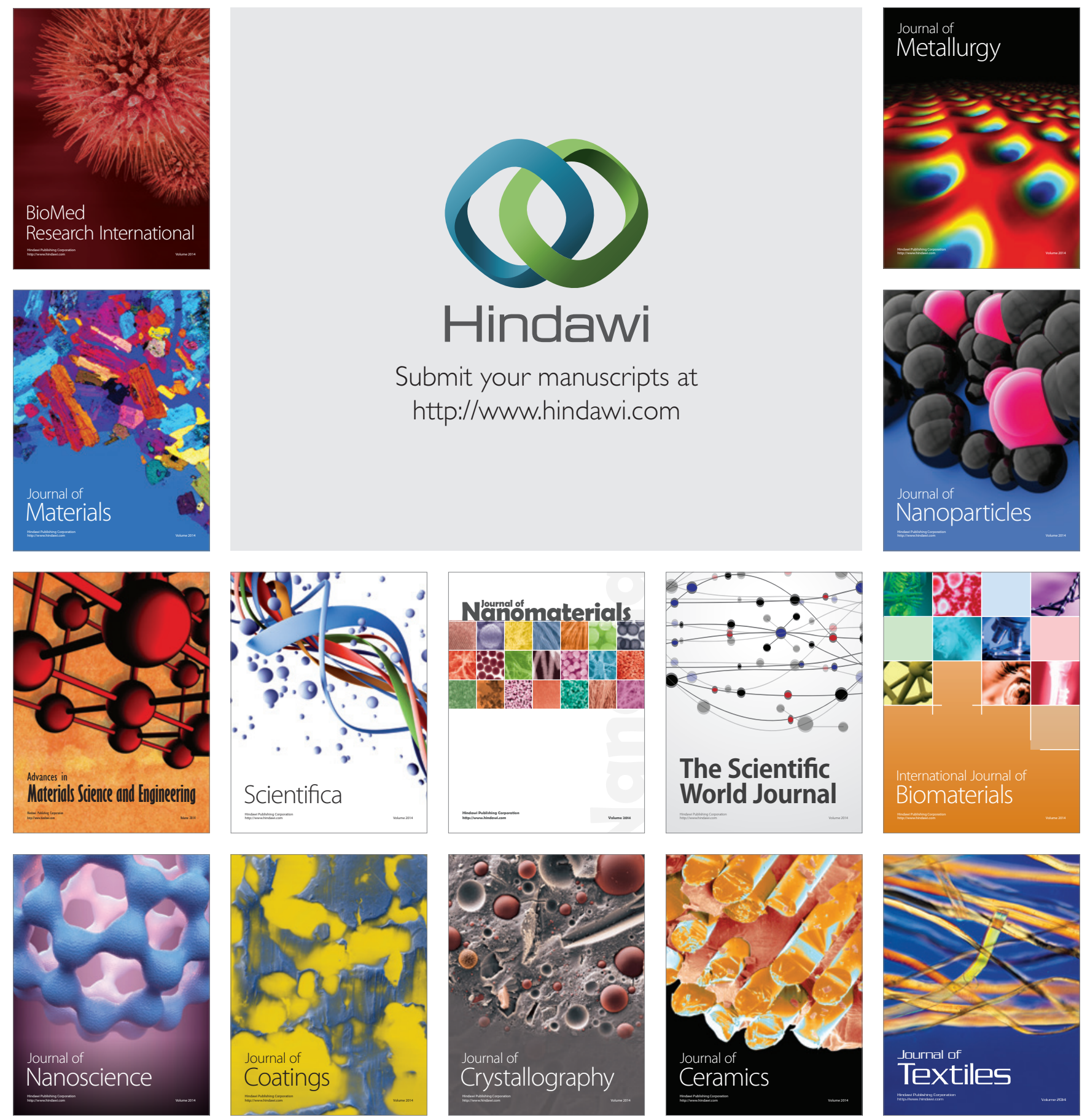